\title{
Excitation of Earth-ionosphere cavity resonances by sprite-associated lightning flashes
}

\author{
Martin Füllekrug \\ Institut für Meteorologie und Geophysik, Universität Frankfurt/Main, Germany
}

\section{Steven C. Reising}

Microwave Remote Sensing Laboratory, University of Massachusetts at Amherst, Massachusetts

\begin{abstract}
Simultaneously recorded discrete excitations of Earth-ionosphere cavity resonances at Silberborn, Germany, and Hollister, California, $9.1 \mathrm{Mm}$ apart, are used to triangulate source locations of lightning flashes in the continental United States with an accuracy of $\sim 0.8 \mathrm{Mm}$, as verified by the National Lightning Detection Network. The identified lightning flashes are mainly associated with positive cloud-toground discharges with first return stroke peak currents $\sim 20-70 \mathrm{kA} . \quad 80 \%$ of these particular lightning flashes are associated with sprites, as verified by simultaneous low-light level TV camera observations at Yucca Ridge, Colorado. This high probability of sprite detection is attributed to particularly large cloud-to-ground lightning currents, simultaneously exciting both Earthionosphere cavity resonances and sprites.
\end{abstract}

\section{Lightning flashes and Earth-ionosphere cavity resonances}

Natural electromagnetic field variations in the 6-60 Hz transition zone between the Ultra-Low Frequency (ULF) and Extremely-Low Frequency (ELF) ranges are characterized by interference of propagating waves in the Earth-ionosphere cavity. These Earth-ionosphere cavity (or Schumann) resonances are mainly excited by globally occurring cloud-to-ground lightning flashes [Sentman, 1995, and references therein] which can be located using singlc station measurements of the vertical electric and horizontal magnetic fields [Jones and Kemp, 1970; Kemp and Jones, 1971]. In this letter, we make use of simultaneously recorded time series of horizontal magnetic field variations in the frequency range $0.2-16 \mathrm{~Hz}$ at Silberborn, Germany $\left(51.8^{\circ} \mathrm{N}, 9.5^{\circ} \mathrm{E}\right)$, and Hollister, California $\left(36.8^{\circ} \mathrm{N}, 121.4^{\circ} \mathrm{W}\right)$, on $\mathrm{Au}-$ gust 1, 1996. Discrete excitations of Earth-ionosphere cavity resonances, which exceed the natural noise background by a factor of two at both locations, are detected and they are denoted "discrete events" in the following text. Since the source location of one discrete event observed worldwide remained ambigious [Ogawa et al., 1967], precise times and locations of lightning flashes in the continental United States reported by the National Lightning Detection Network (NLDN) [Cummins et al., 1998] are used to verify that simultaneously occurring

\section{Copyright 1998 by the American Geophysical Union.}

Paper number 1998GL900133.

0094-8276/98/1998GL900133\$05.00 discrete events at both locations are excited by lightning flashes.

The reported times of lightning flashes are corrected for the time delay introduced by the wave propagation (at a velocity of $0.8 \mathrm{c}$ ) along the great circle path to the receiving stations, and simultaneous occurrence tests $(\leq \pm 15 \mathrm{~ms})$ result in 569 verified discrete events. The horizontal magnetic field of these discrete events is rotated in the direction of maximum magnetic intensity to maximize their signal-to-noise ratio for display. In general, the discrete events exhibit transient pulses at Hollister and damped oscillations of $8 \mathrm{~Hz}$ at Silberborn (see Figure 1). Differences in the wave forms arise from higher order modes in the near field at Hollister ( 1.9 Mm from the source) and Earth-ionosphere cavity resonances at Silberborn $(\sim 7.9 \mathrm{Mm}$ from the source). Arrival azimuths of discrete events are obtained from the angle to rotate the magnetic ficld vector in the direction of maximum magnetic intensity at both locations. The lightning flash locations reported by the NLDN are used to calculate the mean arrival azimuth deviation from the expected orientation of the Poynting vector along the great circle path. The mean arrival azimuth deviations are $5.85^{\circ} \pm 6.31^{\circ}$ and $-1.41^{\circ} \pm 6.08^{\circ}$ clockwise from gcographic north at Silberborn and Hollister respectively. These deviations are

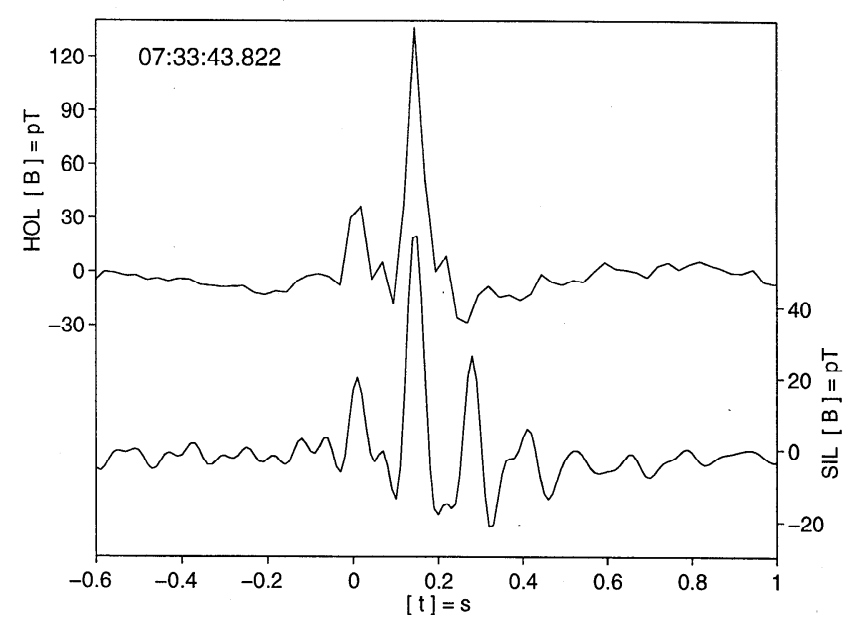

Figure 1. Simultaneously recorded discrete events at Hollister, California (HOL), and at Silberborn, Germany (SIL), displayed in the direction of maximum magnetic intensity. At $\mathrm{t}=+125 \mathrm{~ms}$, a strong positive lightning flash was reported by the NLDN. 


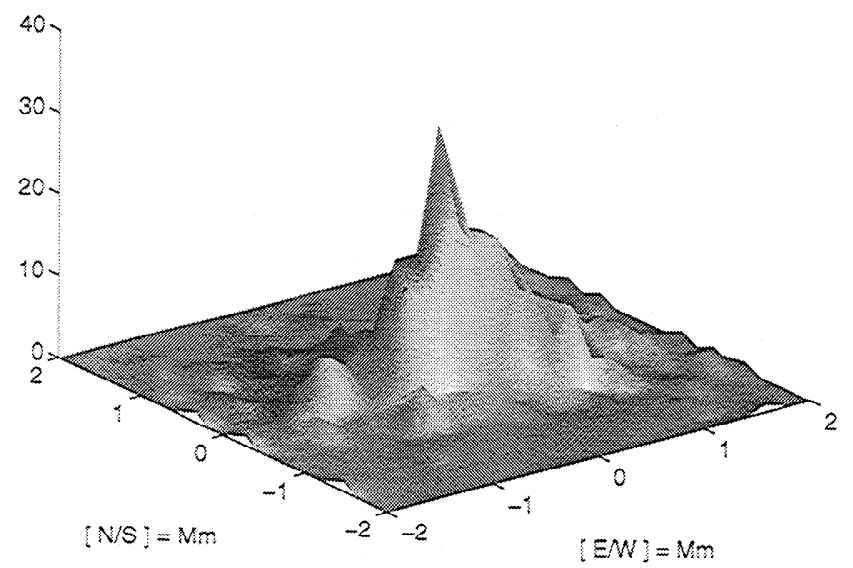

Figure 2. Spatial distribution of the source location triangulation error of 569 lightning flashes, simultaneously recorded at Silberborn, Germany, and at Hollister, California. The mean spatial accuracy is $\sim 0.8 \mathrm{Mm}$, as verified by the NLDN.

presumably accumulated from anisotropic conductivities during the propagation along the great circle path in the Earth-ionosphere cavity. Source location triangulation reveals a spatial accuracy of $\sim 0.8 \mathrm{Mm}$ after removal of the mean arrival azimuth deviation (see Figure 2). Both the arrival azimuth deviation and the spatial accuracy are in agreement with previous estimates [Burke and Jones, 1995; Füllekrug et al., 1996], and we conclude from the coincidence in time and space that these 569 lightning flashes effectively excited Earthionosphere cavity resonances.

All lightning flashes recorded by the NLDN in the United States on August 1, 1996, are shown in Figure 3, left panel. For comparison, the NLDN locations of lightning flashes which simultaneously excite discrete events at, Silberborn and Hollister, are displayed in Figure 3 , right panel. It is evident that the subset of lightning activity derived from globally observable excitations of Earth-ionosphere cavity resonances reflect the main centers of thunderstorm activity in the studied area. In addition to the times and locations of lightning flashes, the NLDN reports the peak current $\left(\mathrm{I}_{\mathrm{p}}\right)$ in the first return stroke of each individual flash. Figure 4 shows the distribution of this peak current for all lightning flashes reported by the NLDN (4A), and for those lightning flashes which excite Earth-ionosphere cavity resonances (4B). The latter are mainly associated with positive first return stroke peak currents $\sim 20-70 \mathrm{kA}$, and we conclude that the discrete events are excited by the occurrence of lightning continuing current, in agreement with the work of Burke and Jones [1996].

\section{Sprites and Earth-ionosphere cavity resonances}

Transient optical emissions in the meso- and ionosphere, denoted sprites [Sentman et al., 1995; Lyons, 1996] and elves [Fukunishi et al., 1996] respectively, are also associated with strong positive cloud-to-ground discharges [Boccippio et al., 1995]. Slow tails of spriteassociated lightning flashes have been observed in the ELF range [Reising et al., 1996; Cummer and Inan, 1997], in the lower ELF range [Boccippio et al., 1995], and in the ELF/ULF transition range [Füllekrug et al., 1996]. A natural question is whether the global excitations of Earth-ionosphere cavity resonances reported in this contribution are related to sprites. Low light level TV (LLTV) camera observations, part of Stanford University's Fly's Eye experiment at Yucca Ridge, Colorado $\left(40.7^{\circ} \mathrm{N}, 104.9^{\circ} \mathrm{W}\right)$, observed sprites above a mesoscale convective system in the midwestern United States on August 1, 1996 [Bell et al., 1998]. The NLDN lightning flashes were preselected in time and space such that any sprites associated with these lightning flashes would have been observed during the operation of the LLTV camera and within its field of view. During the time interval 06:36-08:13 UT, 30 lightning flashes met this criterion and excited Earth-ionosphere cavity resonances. $24(80 \%)$ of these lightning flashes were associated with sprites. The high probability of sprite detection by global excitations of Earth-ionosphere cavity resonances can be explained by particu-
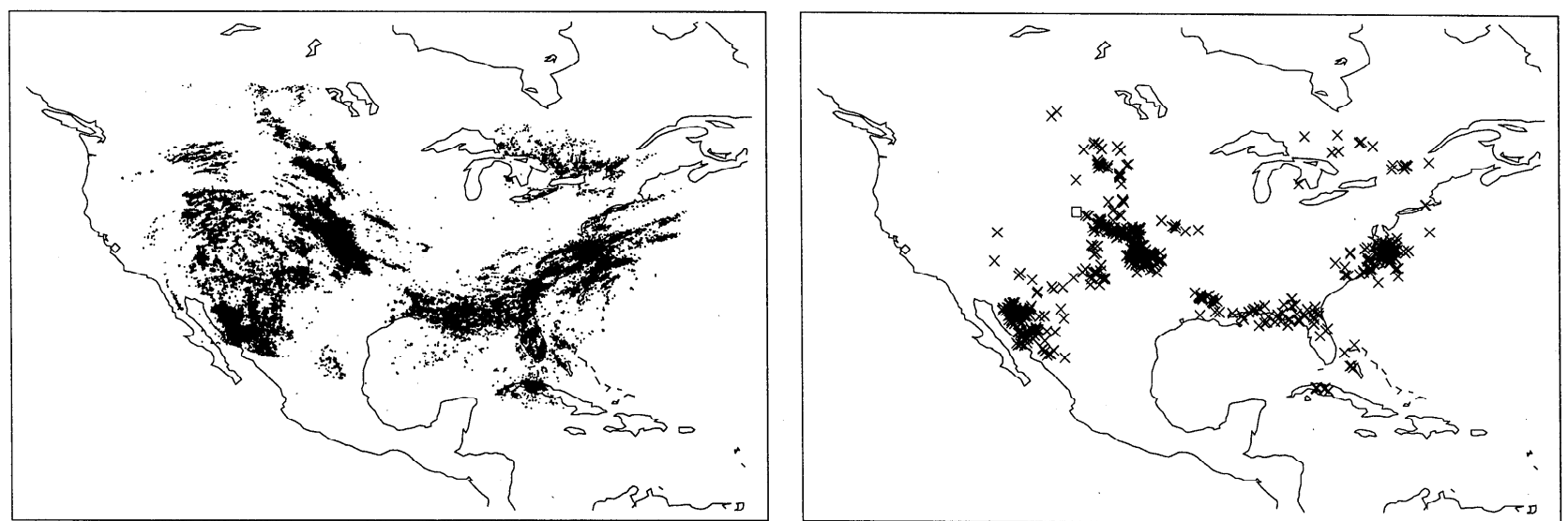

Figure 3. Locations of all lightning flashes recorded by the NLDN on August 1, 1996 (left panel). NLDN locations of lightning flashes which simultancously excite discrete events at Silberborn, Germany, and Hollister, California, are shown in the right panel. These particular lightning flashes reflect the main centers of thunderstorm activity in the studied area. 

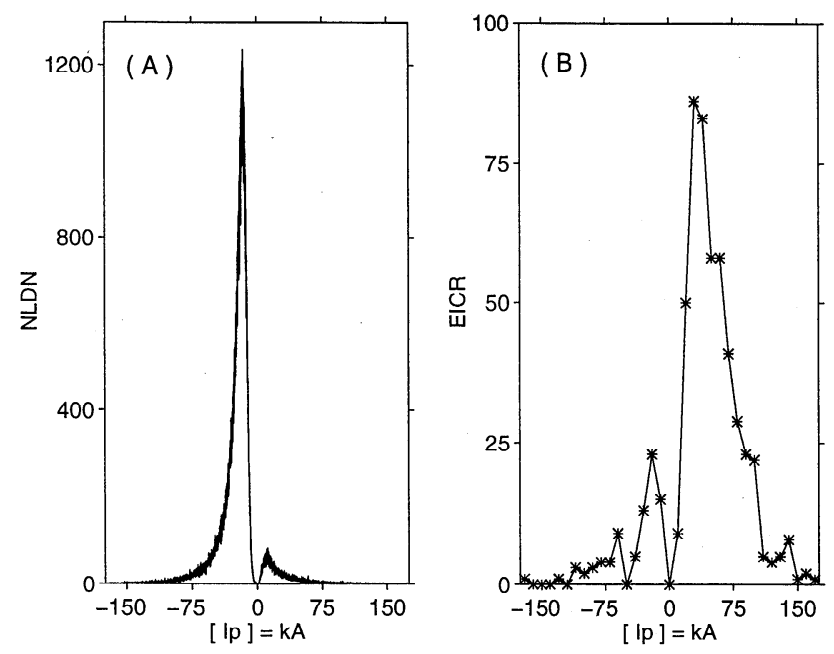

Figure 4. Distribution of first return stroke peak currents $\left(\mathrm{T}_{\mathrm{p}}\right)$ of all lightning flashes recorded by the NLDN on August 1, 1996 (A), and of those lightning flashes which excite Earth-ionosphere cavity resonances (EICR) (B). The latter are mainly associated with positive cloud-to-ground currents $\sim 20-70 \mathrm{kA}$.

larly large currents associated with those lightning discharges which simultaneously excite Earth-ionosphere cavity resonances and sprites. This result may be spatially extended from the field of view of the LLTV camera to the contiguous United States. Under the assumption that such an extension is valid, Figure 3 (right panel) displays predicted sprite locations in the United States, based on the simultaneous detection of discrete excitations of Earth-ionosphere cavity resonances at Silberborn and Hollister. Note that the thunderstorm activity on the East coast and at the Gulf of Mexico mainly occurred during daylight hours, therefore optical observations of sprites would not have been possible. A similar map has been created for Europe (see Figure 5). Now, transient pulses and Earth-ionosphere cavity resonances were recorded at Silberborn and Hollister re-

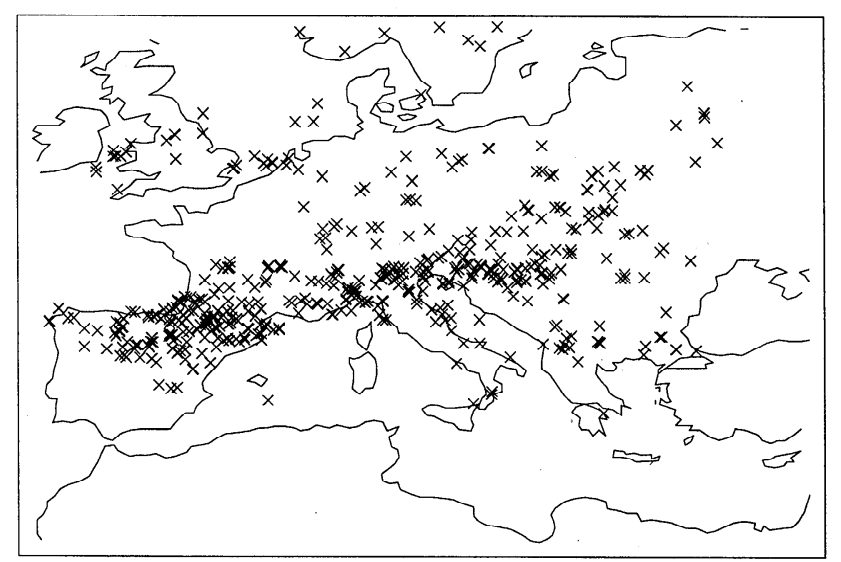

Figure 5. Locations of lightning flashes recorded by the British Meteorological Office, selected by using simultaneously occurring discrete events at Silberborn, Germany, and Hollister, California. The southern side of the Pyrenees and Alps are promising regions of sprite occurrences. spectively. Times and locations of lightning flashes have been reported by the VLF time of arrival differcnce system of the British Meteorological Office [Lee, 1986]. It is evident that thunderstorm activity on the southern side of the Pyrenees and Alps are promising regions of sprite occurrences.

\section{Discussion}

Lightning flashes associated with particularly large currents can simultaneously excite Earth-ionosphere cavity resonances and sprites. This observation may be a consequence of highly variable current within the lightning channel, for example as a result of the redistribution of charges within the thundercloud [Bell et al., 1998]. On the other hand, Cummer et al. [1998] reported enhancements of ELF slow tails $\sim 5 \mathrm{~ms}$ after the initial lightning discharge, coincident with sprite luminosity as verified by use of a high speed photometer. The authors attributed their results to current within the sprite. We extend their ELF observations to measurements in the ELF/ULF transition range from 0.2-16 Hz.

One LLTV frame has a time duration of $33 \mathrm{~ms}$ and in 5 cases out of $66(7.6 \%)$, the sprite occurred 2-6 TV frames after the positive lightning flash (see 'lable 1). At Silberborn and Hollister, the horizontal magnetic intensity $B_{h}=\sqrt{ }\left(B_{x}^{2}+B_{y}^{2}\right)$ is sampled at frequencies of $100 \mathrm{~Hz}$ and $40 \mathrm{~Hz}$, respectively. For example, Figure $6 \mathrm{~A}$ and $6 \mathrm{~B}$ show the horizontal magnetic intensities associated with sprite $(\mathrm{S})$ number $1(6 \mathrm{~A})$ and $2(6 \mathrm{~B})$ at 0.0 seconds. Both are preceded by positive lightning flashes $(+)$ at $\mathrm{t}=-75 \mathrm{~ms}$ and $\mathrm{t}=-150 \mathrm{~ms}$, respectively. Interestingly, the horizontal magnetic intensity during the sprite occurrence is larger than the horizontal magnetic intensity associated with the positive lightning flash. This is a common property of all events listed in Table 1. A third positive lightning flash (48.4 kA) occurs at $t=+450 \mathrm{~ms}$ in cvent number 1 (see 'Figure

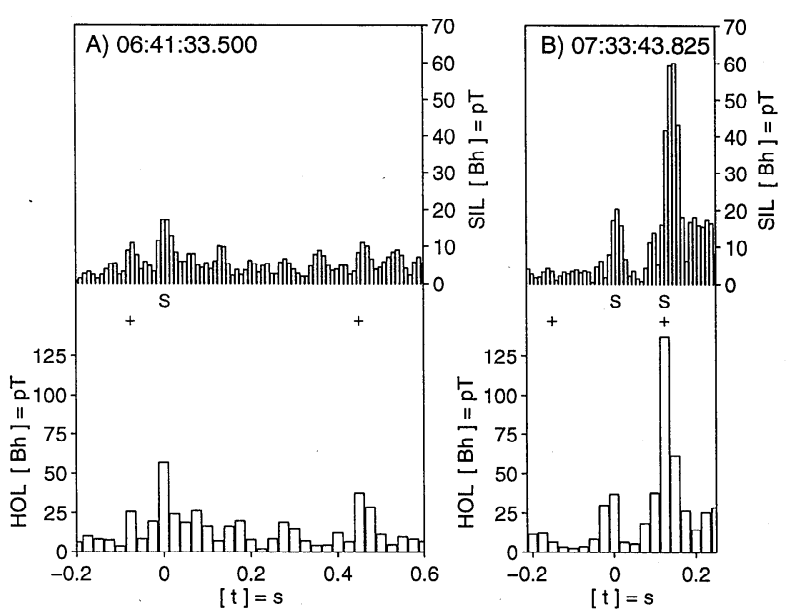

Figure 6. Horizontal magnetic intensity at Silberborn (upper pancls) and Hollister (lower panels). Sprites (S) are reported at 0.0 seconds, preceded by positive lightning flashes $(+)$ at $t=-75 \mathrm{~ms}(\mathrm{~A})$ and $\mathrm{t}=-150 \mathrm{~ms}(\mathrm{~B})$. A positive lightning flash and a sprite occur simultaneously at $\mathrm{t}=+125 \mathrm{~ms}(\mathrm{~B})$ and excite Earth-ionosphere cavity resonances at Silberborn (compare to Figure 1). 
Table 1. Occurrence times of sprites which occur 2-6 TV frames after a positive lightning flash reported by the NLDN on August 1, 1996.

\begin{tabular}{|c|c|c|c|c|c|}
\hline \multirow[b]{2}{*}{ no. } & sprite & \multicolumn{4}{|c|}{ NLDN } \\
\hline & hh:mm:ss.ms & hh:mm:ss.ms & lat. & $\operatorname{lng}$. & $\mathrm{I}_{\mathrm{p}}(\mathrm{kA})$ \\
\hline 1 & $06: 41: 33.512$ & $06: 41: 33.421$ & $38.11^{\circ}$ & $-99.39^{\circ}$ & +102.7 \\
\hline 2 & $07: 33: 43.822$ & $07: 33: 43.675$ & $38.04^{\circ}$ & $-99.03^{\circ}$ & $\begin{array}{r}1 \\
+42.6\end{array}$ \\
\hline 3 & $07: 41: 47.820$ & $07: 41: 47.707$ & $38.15^{\circ}$ & $-98.93^{\circ}$ & $\begin{array}{r}13.2 \\
+33.2\end{array}$ \\
\hline 4 & $07: 55: 36.884$ & $07: 55: 36.783$ & $37.76^{\circ}$ & $-99.48^{\circ}$ & $\begin{array}{r}-23.5 \\
\end{array}$ \\
\hline 5 & 08:08:15.280 & 08:08:15.093 & $38.43^{\circ}$ & $-99.24^{\circ}$ & +23.0 \\
\hline
\end{tabular}

$6 \mathrm{~A})$, unrelated to spritcs. No remarkable horizontal magnetic intensity is evident at Silberborn (Figure 6A and $6 \mathrm{~B}$, upper bars). The horizontal magnetic intensity of event 2 , associated with a simultaneously occurring positive lightning flash and a sprite at $\mathrm{t}=+125 \mathrm{~ms}$, can clearly be observed at Hollister and excites Earth-ionosphere cavity resonances at Silberborn (see Figure 6B and compare to Figure 1). These results are an extension of and in agreement with the work of Cummer et al. [1998]. In this view, superimposed currents of tropospheric positive lightning flashes and mesospheric sprites may effectively excite the Earth-ionosphere cavity.

Acknowledgments. This research was sponsored by the Deutsche ForschungsGemeinschaft under Grant No. Fu 285/3-1. Data collection at Silberborn was sponsored by the Deutsche ForschungsGemeinschaft under Grant No. Schm 101/23-1 and logistically supported by the Max-Planck Institut für Aeronomie Katlenburg/Lindau. Magnetic field measurements at Hollister were generously provided by the Department of Materials Science and Mineral Engincering, and the Seismological Laboratory at UC Berkeley. Data collection and analysis of sprite observations was sponsored by the National Science Foundation under grant ACM-9412287 and by the Office of Naval Research under A ASRRT grant N00014-95-1-1095. The authors thank U. S. Inan, C. P. Barrington-Leigh, S. Hansen and T. F. Bell for the collection of optical data on Sprite occurrence as part of the Fly's Eye Experiment and the British Meteorological Office for access to selected periods of lightning data.

\section{References}

Bell, T.F., S.C. Reising, and U.S. Inan, Intense continuing currents following positive cloud-to-ground lightning associated with red sprites, Geophys. Res. Lett., 25, 1285, 1998.

Boccippio, D.J., E.R. Williams, S.J. Heckman, W.A. Lyons, I.T. Baker, and R. Boldi, Sprites, ELF transients, and positive ground strokes, Science, 269, 1088, 1995.

Burke, C.P., and D.L. Jones, Global radiolocation in the lower ELF frequency band, J. Geophys. Res., 100, 26263, 1995.

Burke, C.P., and D.L. Jones, On the polarity and continuing currents in unusually large lightning flashes from ELF events, J. Atmos. Terr. Phys., 58, 531, 1996.

Cummer, S.A., and U.S. Inan, Measurement of charge transfer in sprite-producing lightning using ELF radio atmospherics, Geophys. Res. Lett., 24, 1731, 1997.
Cummer, S.A., U.S. Inan, T.F. Bell, and C.P. BarringtonLeigh, ELF radiation produced by electrical currents in sprites, Geophys. Res. Lett., 25, 1281, 1998.

Cummins, K.L., M.J. Murphy, E.A Bardo, W.L. Hiscox, R.B. Pyle, and A.E. Pifer, A combined TOA/MDF technology upgrade of the U.S. National Lightning Detection Network, J. Geophys. Res., 103, 9035, 1998.

Fukunishi, H., Y. Takahashi, M. Kubota, K. Sakanoi, U.S. Inan, and W.A. Lyons, Elves: Lightning-induced transient luminous events in the lower ionosphere, Geophys. Res. Lett., 23, 2157, 1996.

Füllekrug, M., S.C. Reising, and W.A. Lyons, On the accuracy of arrival azimuth determination of sprite-associated lightning flashes by Earth-ionosphere cavity resonances, Geophys. Res. Lett., 23, 3691, 1996.

Jones, D.L., and D.T. Kemp, Experimental and theoretical observation on the transient excitation of Schumann resonances, J. Atmos. Terr. Phys., 32, 1095, 1970.

Kemp, D.T., and D.L. Jones, A new technique for the analysis of transient ELF elctromagnetic disturbances within the Earth-ionosphere cavity, J. Atmos. Terr. Phys., 33, 567, 1971.

Lee, A.C., An experimental study of the remote location of lightning flashes using a VLF arrival time difference technique, Q. J. R. Meteorol. Soc., 112, 203, 1986.

Lyons, W.A., Sprite observations above the U. S. High Plains in relation to their parent thunderstrom systems, J. Geophys. Res., 101, 29641, 1996.

Ogawa, T., M. Yasuhara, A.C. Fraser-Smith, and R. Gendrin, Worldwide simultaneity of occurrence of a Q-type ELF-burst in the Schumann resonance frequency range, J. Geomag. Geoelec., 19, 377, 1967.

Reising, S.C., U.S. Inan, T.F. Bell, and W.A. Lyons, Evidence for continuing currents in sprite-producing lightning flashes, Geophys. Res. Lett., 23, 3639, 1996.

Sentman D.D., Schumann Resonances, in Handbook of Atmospheric Electrodynamics, edited by H. Volland, pp. 267-310, CRC Press, Boca Raton, 1995.

Sentman, D.D., E.M. Wescott, D.L. Osborne, D.L. Hampton, and M.J. Heavner, Preliminary results from the Sprites94 aircraft campaign: 1. Red sprites, Geophys. Res. Lett., 22, 1205, 1995.

M. Füllekrug, Institut für Meteorologie und Geophysik, Feldbergstr. 47, Universität Frankfurt/Main, D-60323 Frankfurt/Main, Germany

S.C. Reising, Microwave Remote Sensing Laboratory, University of Massachusctts at $\Lambda$ mherst, Amherst, MA 01003-4410, USA

(Received August 10, 1998; accepted September 23, 1998.) 